\title{
Zur titrimetrischen Bestimmung der Phosphorsäure mittelst Mo-
} lybdänsäure. Bei der Analyse von Knochenmehlen, in denen die organische Substanz'nicht vollständig zerstört worden war, beobachtete A. Grete*), dass nach Zusatz der ersten Tropfen der Molybdänsäurelösung eine weisse flockige Fällung entstand, welche sich bei fortgesetztem Zusatz von Molybdänsäurelösung in den gewöhnlichen gelben Niederschlag amzuwandeln schien.

Die Vermuthung, dass jener weisse Niederschlag durch Anwesenheit von Leim hervorgerufen sei, bestätigte sich vollkommen, da es gelang, die gesammte Phosphorsäure einer Lösung nach Zusatz von genügenden Leimmengen in Form dieses flockigen, bei grösserer Concentration der Lösungen käsigen Niederschlages auszufällen. Dagegen schlugen alle Versuche, in der Kälte auf diese Weise constant zusammengesetzte Niederschläge zu erhalten, fehl; je mehr Leim vorhanden war, desto mehr nahmen die Niederschläge offenbar auf. Auch in der Hitze zeigte schon das Aeussere des Niederschlages dessen wechselnde Zusammensetzung bei verschiedenen Leimmengen.

Die eben angedeuteten Reactionen verwerthet der Verfasser bei folgendem Verfahren:

Eine abgemessene Menge einer Phosphorsäure enthaltenden Lösung wird im Becherglase unter Anwendung von Methylorange neutralisirt, eventuell eine schwache Füllung mit einigen Tropfen Salpetersäure wieder gelöst. Sodann fügt man ein der Phosphorsäurelösung etwa gleiches Volumen einer concentrirten Lösung von Ammoniumnitrat (75 procentig), sowie ungefähr $1 \mathrm{~g}$ Natriumsulfat nebst $1 \mathrm{cc}$ einer Leimlösung (siehe später) hinzu und erhitzt auf circa $80-90^{\circ} \mathrm{C}$. Die so zubereitete Flüssigkeit wird nun mit der später beschriebenen Molybdatlösung unter häufigem Umschwenken direct titrirt, bis die klare Flüssigkeit nach Zufügen eines Tropfens keine Fällung in Form einer dunklen Wolke mehr zeigt.

Der bei Beginn der Titration erzeugte dicke, weisse Niederschlag wird nach Zufügen grösserer Molybdänsäuremengen allmählich käsiger und gelber, so dass sich auf diesem Untergrunde neue Fällungen, die anfangs weiss sind, sehr gut abheben. Nach tüchtigem Umschwenken der Flüssigkeit probirt man von neuem, indem man von Zeit zu Zeit nur so lange wenig Leimlösung zufügt, als diese allein noch Trübung

*) Ber. d. deutsch. chem. Gesellsch. zu Berlin 21, 2762. 
hervorruft, und erkennt an der abnehmenden Stärke der Reaction das herannahende Ende der Operation. Lä̀sst sich eine Fällung durch Einfall der Titerflüssigkeit in die Phosphorsäurelösung nicht mehr von oben erkennen, und ruft zugefügte Leimlösung keine weisse Trübung mehr hervor, so erhitzt man die möglichst heiss gehaltene Flüssigkeit so lange unter Umrühren, bis der käsige Niederschlag feinkörnig wird. In der klaren Flüssigkeit lässt sich nun beim Hindurchsehen ron der Seite selbst die geringste durch Molybdänsäurelösung hervorgerufene Trübung beobachten, nach deren Entstehen jeweils die Flüssigkeit wieder durch Umsschwenken geklärt wird.

Hat man aus Versehen zu viel Molybdänsäurelösung einfliessen lassen, so kann nach Zufügen von einigen Cubikcentimetern Phosphorsäurelösung durch erneutes Hervorrafen der Endreaction der Fehler verbessert werden.

Nach den bisher gemachten Erfahrungen ist hervorzuheben, dass Anwesenheit von Ammoniumnitrat in steigenden Mengen die Resultate erniedrigt, dass sie aber bei Anwendung der oben angegebenen Verhältnisse constant werden. Umgekehrt erhöhen schwefelsaure Salze die Resultate um etwas, bis sie schliesslich ebenfalls constant werden. In gleicher Weise wirken wechselnde Mengen Säure, welche daher vorher abgestumpft werden müssen; dagegen scheint die mit der Titerflüssigkeit hinzukommende Säure die Vergleichbarkeit der Resultate nicht zu stören, vielleicht weil deren Menge dem zugefügten Flüssigkeitsquantum proportional ist, eventuell zufällig nur so viel betrug, als zur Bildung des Niederschlages erforderlich war. Chlorverbindungen haben in geringer Menge keinen merklichen Einfluss auf das Resultat.

Die nöthigen Lösungen werden folgendermaassen bereitet:

1) Molybdäñsäurelösung. $1 \mathrm{~kg}$ Ammoniummolybdat in ammoniakalischem Wasser gelöst und $100 \mathrm{~g}$ Gelatine mit Wasser und wenig Salpetersäure einige Zeit gekocht, werden gemischt und die schwach alkalische, gelbe Flüssigkeit in circa 3 Liter concentrirte Salpetersäure (spec. Gewicht 1,2) gegossen. Die Mischung wird auf 10 Liter gebracht und mehrere Tage unter Umschütteln aufbewahrt. Es setzt sich bald ein phosphorsäurehaltiger, flockiger Niederschlag ab, nach dessen Entfernung die Lösung vollkommen klar und haltbar ist (während ohne Leimzusatz bekanntlich gelbe Ausscheidungen sich bilden).

2) Concentrirte Lösung von Ammoniumnitrat, 75 procentig, welche pro Liter circa $40 \mathrm{~g}$ Natriumsulfat enthält. 
3) Leimlösung. $100 \mathrm{~g}$ Gelatine werden mit Wasser und etwa $50 \mathrm{cc}$ Salpetersäure gekocht und auf $1000 \mathrm{cc}$ aufgefüllt. Einige Cubikcentimeter dieser Lösung genügen zur Ausfällung von $0,1 g \mathrm{P}_{2} \mathrm{O}_{5}$. Enthält die Leimlösung Phosphorsäure, was sehr häufig vorkommt, so muss diese vorerst entfernt werden.

Die mitgetheilten Beleganalysen sind zufriedenstellend.

Ueber die quantitative Bestimmung des Rhodanwasserstoffs. Peter Klason*) hat gezeigt, dass man den Rhodanwasserstoff ebenso genau wie die Salzsäure mit Silberlösung und neutralem chromsaurem Kali als Indicator titriren könne.

J. Volhard**) hat bekanntlich die Titrirung des Silbers mittelst Rhodanammoniums eingeführt. Klason hat nun umgekehrt den Rhodanwasserstoff in saurer Lösung in der Weise bestimmt, dass er zu der za untersuchenden schwefelsauren Lösung überschüssige Silberlösung hinzufügte, mit Eisenalaunlösung versetzte und hierauf mit 1/100 NormalRhodanammoniumlösung zurücktitrirte, bis Färbung eintrat. Diese Methode gab wenigstens ebenso genaue Resultate wie die erste.

Die beiden erwähnten Methoden sind aber von wenig praktischer Bedeutung für die Bestimmung des Rhodanwasserstoffs, weil keine Salzsäure dabei anwesend sein darf.

Auf die leichte Oxydation des Rhodanwasserstoffs mittelst Kaliumpermanganats in saurer Lösung zu Cyanwasserstoff und Schwefelsäure kann ebenfalls die Bestimmung des Rhodanwasserstoffs gegründet werden. Bei dieser Methode ist anwesende Salzsäure ohne Einfluss, und hat sogar Volhard***) vorgeschlagen, den Oxydationswerth des Permanganats durch eine sehr verdünnte Lösung von Rhodanammonium festzustellen.

Man braucht hier nicht wie bei der Oxydation von Oxalsäure die Lösung zuerst zu erwärmen, indem die Reaction schon bẹ gewöhnlicher Temperatur eintritt; am besten vollzieht sich dieselbe in salzsaurer Lösung. Der Endpunkt ist ebenso scharf wie bei der Oxydation von Oxalsäure. Man sollte also glauben, dass Rhodanwasserstoff sich scharf nach dieser Methode bestimmen lasse.

Von Klason angestellte Versuche zeigten jedoch, dass man nach

*) Journ. für praktische Chemie [N. F.] 36, 74.

**) Diese Zeitschrift 13, 171, 17, 482 und 18, 271.

***) Diese Zeischrift 18, 291. 